\title{
Size effect on post-cracking strength of high performance fibre-reinforced concrete
}

\author{
Eduardo Galeote $^{\mathrm{a}}$, Ana Blanco ${ }^{\mathrm{b}}$, Albert de la Fuente ${ }^{\mathrm{b}}$, Chris Goodier ${ }^{\mathrm{c}}$, Simon Austin ${ }^{\mathrm{c}}$ \\ ${ }^{1}$ Department of Civil and Environmental Engineering, Universitat Politècnica de \\ Catalunya, Jordi Girona 1-3, 08034 Barcelona, Spain. \\ ${ }^{2}$ School of Civil and Building Engineering, Loughborough University, Loughborough, \\ Leicestershire LE11 3TU, United Kingdom.
}

\begin{abstract}
The size effect is a well-known phenomenon in the design of reinforced concrete structures. Although it has been studied extensively for conventional concrete with or without traditional reinforcement, its influence on the post-cracking behaviour of fibrereinforced composites is scarcely reported in literature. This is particularly true in the case of high performance fibre-reinforced concrete (HPFRC), which allows the design of very thin elements and whose behaviour may be highly influenced by their size. The aim of this research was to evaluate the influence of the size of HPFRC beams on the mechanical performance at a cross-sectional level. An experimental program involving three-point bending tests of HPFRC on beams of dimensions $40 \times 40 \times 160,100 \times 100$ x 400 and $150 \times 150 \times 600 \mathrm{~mm}$ was conducted. Three steel fibre contents were investigated: 90,140 and $190 \mathrm{~kg} / \mathrm{m}^{3}$. These bending tests were also simulated via a sectional analysis model, taking as a reference the constitutive law described in the fib Model Code for Concrete Structures 2010. The results suggest that the values of stress in the constitutive model should depend upon the cross-sectional size of the beam. This is reflected when adjusting the parameters of the MC2010 to fit the experimental values, resulting in a coefficient of determination above 0.88 when comparing the ratio between these two parameters and the size of the cross section.
\end{abstract}

Keynotes: HPFRC, size effect, bending test, inverse analysis, constitutive model.

\section{INTRODUCTION}

The greater strength of high performance fibre-reinforced concrete (HPFRC) has become an asset for the construction and design of new structures. Enhanced properties allow the reduction of sectional dimensions, even though the material properties of HPFRC might be different when using various section sizes due to the size effect. Regarding the testing and characterization process, this should be considered and taken into account since reducing the dimensions of the specimens could simplify the tests and test procedures.

Smaller samples might be more representative of more slender elements, which may be among the typical structures designed with HPFRC. From a design point of view, 
the use of smaller beams to identify parameters for design purposes is a topic that has been already studied [1]. Even though the size effect in HPFRC has been recently addressed [2]-[4] through different approaches, a better understanding of the influence of size effect is lacking. The aim of this paper is to analyse the influence of the size effect on the constitutive law defined by the fib Model Code 2010 [5].

For this purpose, an experimental program involving three mixes of HPFRC with different fibre contents was conducted. The flexural strength was determined via threepoint bending tests using prismatic specimens of three different dimensions. The influence of the size of the specimen is inferred and the results of the bending tests are used to define the constitutive law described in the fib Model Code 2010. In this regard, the constitutive model is simulated using an inverse analysis and the results of this model are compared to the experimental values.

\section{EXPERIMENTAL PROGRAM}

Based on previous experiences on the use of HPFRC, three mixes with fibre contents of 90,140 and $190 \mathrm{~kg} / \mathrm{m}^{3}$ were designed and produced. A water-cement ratio of 0.229 was established since lower ratios did not provide an appropriate workability. The content of silica sand was slightly modified in the mixes with higher fibre contents to obtain the desired consistency. Due to its high specific surface area, nanosilica was introduced as a highly reactive pozzolanic material into all mixes at a content of $5 \%$ over the cement weight. Further details of the concrete composition are shown in Table 1, as well as the properties of the fibres, which are also described in Table 2.

Table 1. Concrete mixes $\left[\mathrm{kg} / \mathrm{m}^{3}\right]$.

\begin{tabular}{llll}
\hline Materials & M90 & M140 & M190 \\
\hline CEM I 52.5R & 800 & 800 & 800 \\
Silica sand 3-4 mm & 1131 & 1108 & 1098 \\
Filler (CaCO 3$)$ & 200 & 200 & 200 \\
Water & 129 & 129 & 129 \\
Superplasticizer & 32 & 32 & 32 \\
Nanosilica & 40 & 40 & 40 \\
Steel fibres & 90 & 140 & 190 \\
\hline
\end{tabular}

Table 2. Steel fibres characteristics.

\begin{tabular}{ll}
\hline Characteristics & \\
\hline Fibre shape & Straight \\
Length [mm] & 13 \\
Diameter [mm] & 0.20 \\
Tensile strength [MPa] & 2750 \\
Elastic modulus [GPa] & 200 \\
\hline
\end{tabular}

The results of the characterization of the four concretes are presented in Table 3, along with their coefficient of variation. The elastic modulus was determined using cylindrical specimens of $\phi 150 \times 300 \mathrm{~mm}$ [6]. The compressive strength was tested using 
cubic casted specimens of 150x150 mm [7] and the flexural strength by means of the three-point bending test (3PBT) in casted specimens of 150x150x600 mm [8].

In total, 3 samples with dimensions of 150x150x600 mm, 6 samples of 100x100x400 $\mathrm{mm}$ and 9 samples of 40x40x160 mm (150, 100 and $40 \mathrm{~mm}$ hereinafter) were casted per each mix and tested under a 3PBT configuration to evaluate the influence of the size effect. The ratios of depth-span and depth-notch were kept constant in order to maintain the proportions between the dimensions of the beams.

Table 3. Average mechanical properties of the mixes.

\begin{tabular}{|c|c|c|c|c|c|c|}
\hline \multirow[t]{2}{*}{ Properties } & \multicolumn{2}{|l|}{ M90 } & \multicolumn{2}{|l|}{ M140 } & \multicolumn{2}{|l|}{ M190 } \\
\hline & $\begin{array}{c}\text { Average } \\
{[\mathrm{MPa}]}\end{array}$ & $\begin{array}{l}C V \\
{[\%]}\end{array}$ & $\begin{array}{c}\text { Average } \\
\text { [MPa] }\end{array}$ & $\begin{array}{l}C V \\
{[\%]}\end{array}$ & $\begin{array}{c}\text { Average } \\
\text { [MPa] }\end{array}$ & $\begin{array}{l}C V \\
{[\%]}\end{array}$ \\
\hline$E_{\mathrm{cm}}$ & 36337 & 0.5 & 35469 & 1.2 & 37674 & 0.5 \\
\hline $\mathrm{f}_{\mathrm{cm}}$ & 115.9 & 0.7 & 108.8 & 1.9 & 117.2 & 0.5 \\
\hline $\mathrm{f}_{\mathrm{LOP}}$ & 8.02 & 6.5 & 8.93 & 2.7 & 9.54 & 6.8 \\
\hline $\mathrm{f}_{\mathrm{R} 1}$ & 14.58 & 5.8 & 20.05 & 1.2 & 17.83 & 7.6 \\
\hline $\mathrm{f}_{\mathrm{R} 2}$ & 14.63 & 4.0 & 19.41 & 5.9 & 16.96 & 2.7 \\
\hline $\mathrm{f}_{\mathrm{R} 3}$ & 13.03 & 3.8 & 17.35 & 4.3 & 14.73 & 4.6 \\
\hline $\mathrm{f}_{\mathrm{R} 4}$ & 11.18 & 3.7 & 14.44 & 2.4 & 11.99 & 4.3 \\
\hline
\end{tabular}

\section{ANALYSIS OF RESULTS}

\section{Experimental results}

Figure 1 shows the average flexural strength calculated as described in [8] for the three different specimen sizes, for each of the three mix designs, and for Crack Mouth Opening Displacement (CMOD) up to $4 \mathrm{~mm}$. It may be observed that changing the dimensions of the cross-section produced different effects depending on the fibre content of the mix. It has been previously reported that as the size of the specimen decreases, so does the flexural strength capacity [9]. However, in the light of the results obtained here, this conclusion might be influenced by additional factors.
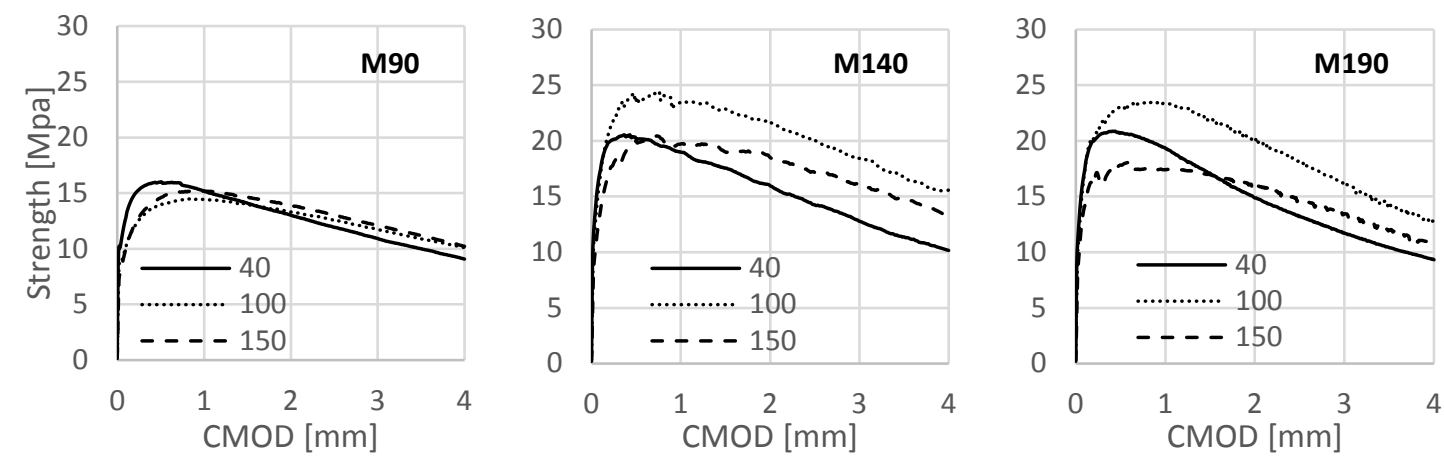

Figure 1. Average flexural strengths of M90, M140 and M190.

As expected, the lowest flexural strengths among the three mixes were those obtained for the mix with a fibre content of $90 \mathrm{~kg} / \mathrm{m}^{3}$. Nevertheless, although the strengths for M140 and M190 are higher than for M90, increasing the amount of fibres from 140 to 
$190 \mathrm{~kg} / \mathrm{m}^{3}$ did not entail any significant improvement in performance. In fact, the strength of the 150 and $100 \mathrm{~mm}$ specimen in M190 was lower than for M140.

For the mix M90, similar results were obtained for the three sizes of specimens. The maximum flexural strength was obtained for the $40 \mathrm{~mm}$ specimen and was only $10.6 \%$ higher than the maximum obtained for the $100 \mathrm{~mm}$ specimen. The post-cracking branch after the maximum strength follows a similar trend for the three specimen sizes, with a maximum difference between them of $11.7 \%$.

For mixes M140 and M190 the differences in the results become more evident. In both cases, the maximum flexural strength is achieved with the $100 \mathrm{~mm}$ specimen. During the initial part of the test, the $40 \mathrm{~mm}$ specimen presents a greater strength than the 150 $\mathrm{mm}$, although this trend is reversed at the last stage of the test. It must also be pointed out the strong similarity between the results of M140 and M190, especially for the specimens of $40 \mathrm{~mm}$ and $100 \mathrm{~mm}$, even though there is a difference in the weight of fibres of $50 \mathrm{~kg} / \mathrm{m}^{3}$. This may be caused by a double effect experienced by the material: one related to the change of the dimension of the specimen itself and the other as a consequence of the distribution of the fibres into the cross-section. The latter effect is also reported as the main reason for the size effect in HPFRC in [10].

Figure 2 shows the distribution profile of fibres within the cross-sectional area of a prismatic specimen [11], [12] with a height $h$ and a width $b$. Due to the wall-effect and its influence on the position of the fibres, the orientation number $(\eta)$ varies depending on the zone of the section $\left(\eta_{1}>\eta_{2}>\eta_{3}\right)$. The zones are defined by the specimen dimension and the fibre length $l_{f}$. Reducing the section decreases the area of zones 2 and 3 and puts more weight on zone 1 , thus increasing the overall orientation number at the cross-section. Hence, once a certain content of fibres is achieved it may be possible that keeping on increasing it does not entail any additional advantage in terms of performance.

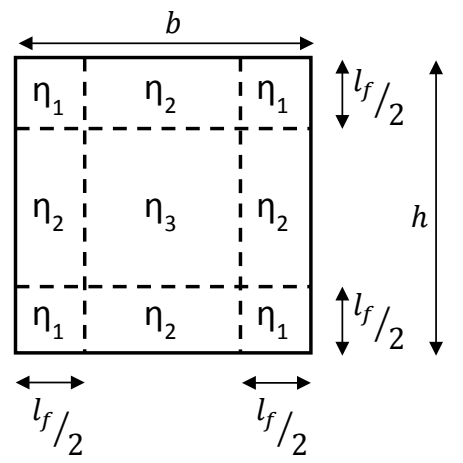

Figure 2. Distribution profile of fibres.

\section{Model type and input parameters}

To analytically simulate the results of the bending tests, an Analysis of Evolutionary Sections (AES) was used as described in [13]. The AES consists of an inverse analysis and is based on several assumptions which verify the following hypothesis: (i) sections remain plane after loading or imposed strains; (ii) perfect bond between concrete and fibres is assumed; (iii) shear stress strains are negligible and not considered.

The constitutive law that describes the post-cracking behaviour of FRC in the Model Code 2010 was implemented using the AES. The linear model, which is able to identify 
a softening or hardening post-cracking behaviour, was chosen to perform the numerical simulations. The characteristic length, which is the parameter that allows for the determination of the crack opening out of the strain, was defined to be equal to the depth of the beam $\left(l_{c s}=h\right)$, despite several authors proposing different values for this parameter [14]. The strength parameters defining the constitutive law were those belonging to each specimen size.

\section{Comparison with the fib Model Code 2010}

The estimated results of the inverse analysis were plotted along with the average values of the experimental results (Figure 3). As may be observed, there are significant differences regarding how the MC2010 adjusts the results for the different sizes of the specimens.
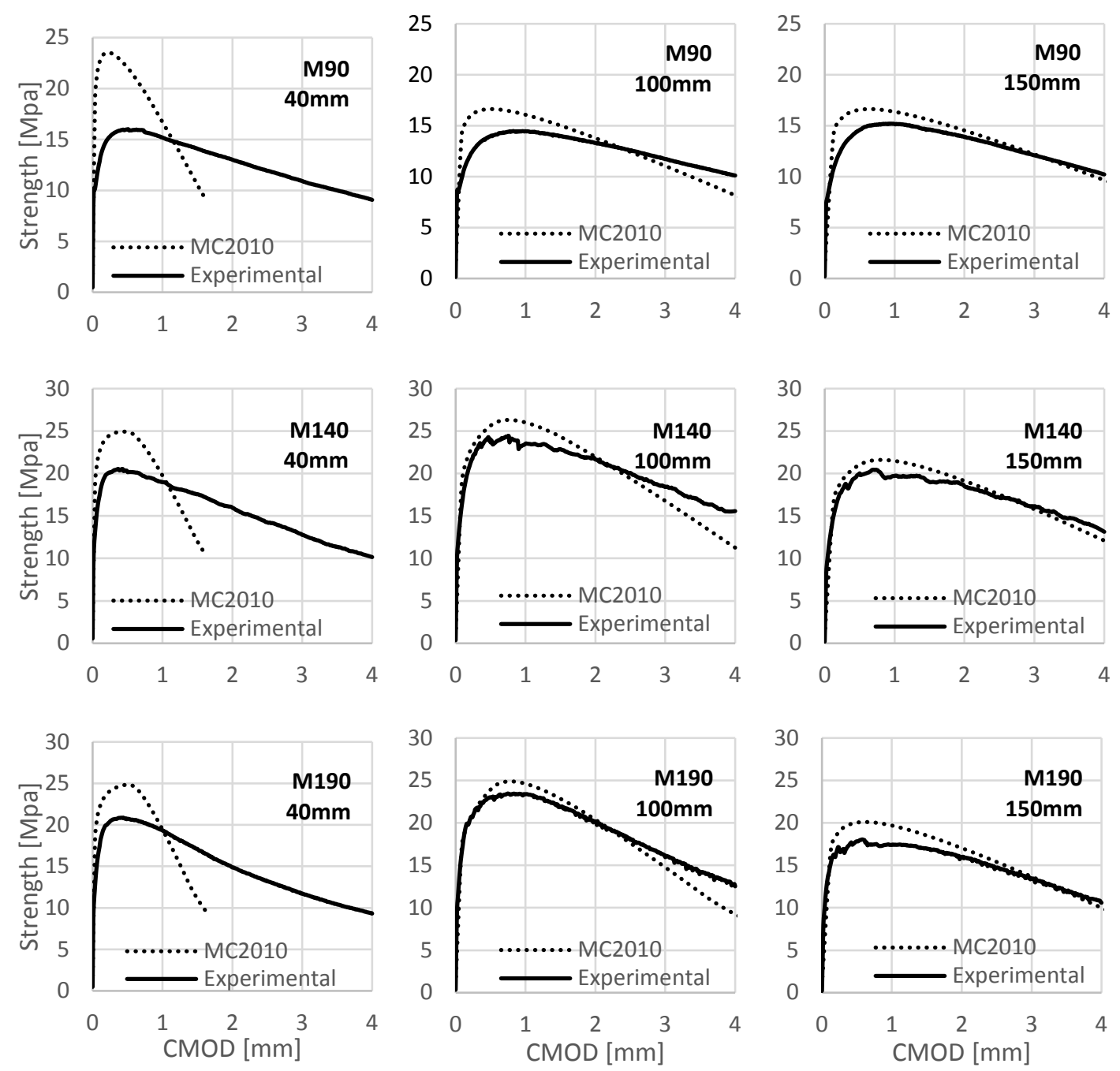

Figure 3. Comparison between experimental and MC2010 results.

It may be seen that the analytical model follows broadly the trend shown by the experimental results of the 150 and $100 \mathrm{~mm}$ beams. Conversely, the analytical results 
obtained for the $40 \mathrm{~mm}$ specimens differ greatly with respect to the experimental values of these specimens. These differences are a direct consequence of developing the constitutive law based on the performance of larger specimens.

In every case analysed, the analytical model overestimates the strength at the SLS region $\left(f_{R 1}\right)$, with the difference being more evident with the smallest specimens. In fact, the difference in $f_{R 1}$ for the $40 \mathrm{~mm}$ samples is $37.7 \%$ for M90, and $19.9 \%$ for M190. Also, in these specimens, from a crack opening of $1 \mathrm{~mm}$ onwards, the analytical model presents lower results than the experimental values. For the 100 and $150 \mathrm{~mm}$ specimens the model represents with more accuracy the real behaviour of the specimens, although some differences may still be found. Regarding the strength $f_{R 1}$, the maximum difference achieved between the model and the experimental result was $13.6 \%$ for both sizes. The model was capable of fitting better the strength $f_{R 3}$, with an average difference of $2.7 \%$ and a maximum of $4.7 \%$.

For the smallest specimens, the analytical model was not able to represent the whole experimental curve. The strains at the top and the bottom of the section, shown in Table 4 , are proportionally much higher for the smaller samples, thus reducing the extent of crack opening $(\omega)$ that the model is able to reproduce.

Table 4. Distribution of strains at the cross section with fib MC2010.

\begin{tabular}{lccccc}
\hline $\begin{array}{l}\text { Size of } \\
\text { specimen }\end{array}$ & $\begin{array}{c}\varepsilon_{\text {top }} \\
(\% 0)\end{array}$ & $\begin{array}{c}\varepsilon_{\text {bot }} \\
(\% 0)\end{array}$ & $\begin{array}{c}l_{c s} \\
(\mathrm{~mm})\end{array}$ & $\begin{array}{c}\omega=\varepsilon_{\text {bot }} \cdot l_{c s} \\
(\mathrm{~mm})\end{array}$ & Strain diagram \\
\hline $40 \mathrm{~mm}$ & -3.5 & 20.05 & 33.3 & 0.67 \\
$100 \mathrm{~mm}$ & -3.5 & 20.05 & 83.3 & 1.67 \\
$150 \mathrm{~mm}$ & -3.5 & 32.05 & 125 & 4.00 & $\varepsilon_{\text {bot }}$
\end{tabular}

\section{Calibration of the constitutive law}

Given the differences between the analytical and the experimental results, the parameters used to define the constitutive law are adjusted here to obtain a better fitting between the analytical and the experimental curves. In this regard, only the parameters related to the strength defining the post-cracking behaviour $\left(f_{F t s}, f_{F t u}\right)$ are analysed. Figure 4 shows the ratio between the parameters of the constitutive law calculated as described in MC2010 $\left(f_{F t s}, f_{F t u}\right)$ and the modified parameters $\left(f_{F t s}^{*}, f_{F t u}^{*}\right)$ to fit the analytical results to the experimental curve.

Greater values for the ratios reveal larger differences between the experimental results and the model. It may be observed that this effect is more pronounced as the size of the specimen decreases, although this tendency seems to stabilize when the dimensions of the specimen increase. The constitutive law is defined based on the results of the 150 $\mathrm{mm}$ specimens instead of the smaller samples. The differences in performance, depending on the size of the specimens, as shown in Figure 1, lead to input parameters in the constitutive law which produce less accurate fittings of the analytical model to the experimental values. 
The results of the ratios calculated also follow a logarithmic trend with a determination coefficient above 0.88. As seen in the comparison between the experimental results and MC2010, the model overestimated the results in the SLS region. Moreover, the difference between the model and the experimental results was higher in the SLS region than the ULS, thus increasing the difference between $f_{F t s}-f_{F t s}^{*}$ and $f_{F t u}-f_{F t u}^{*}$. This has resulted in higher ratios of $f_{F t s} / f_{F t s}^{*}$ than for $f_{F t u} / f_{F t u}^{*}$.

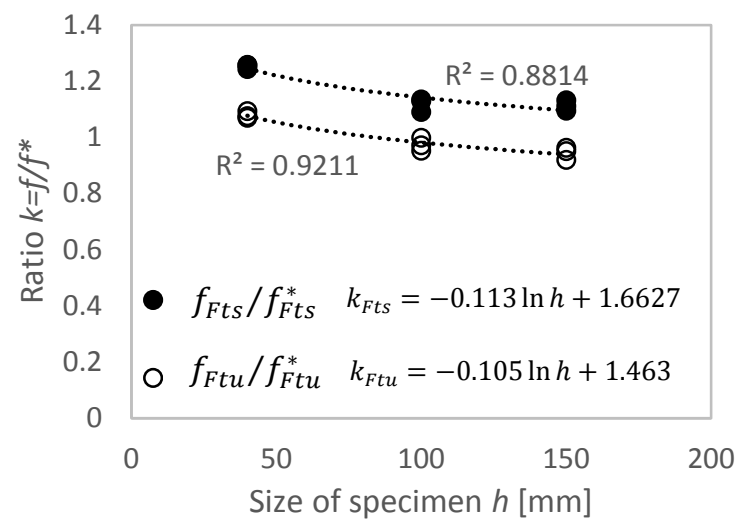

Figure 4. Ratio between MC2010 and the adjusted parameters.

\section{CONCLUSIONS}

A clear size effect is confirmed from the study of HPFRC specimens in both the experimental results and the analytical values obtained with the inverse analysis. Based on these results, several conclusions may be drawn:

- The size of the specimen has a clear effect on the performance of the HPFRC. Nevertheless, there is not a clear trend regarding which size of specimen shows a greater performance, although smaller specimens generally lead to greater strengths.

- Two types of size effect occur in HPFRC. One is produced as a result of changing the size of the sample, and the other is due to the distribution of the fibres within the cross-sectional area.

- The constitutive model based on the fib Model Code 2010 overestimates the results within the SLS region, and the maximum flexural strength. It is also not capable of reproducing the entire performance curve for specimens $40 \mathrm{~mm}$ in size, since extremely high strains occur at the bottom section.

- As the size of the test specimen increases, the constitutive law adjusts better the analytical values compared to the experimental results. Also, the trend of the curve obtained from the analytical model successfully follows the trend shown by the experimental results.

- The ratio between the adjusted and the original input parameters increases as the specimen size decreases. This is due to a less accurate fitting between the model and the experimental results for smaller beams. 


\section{ACKNOWLEDGEMENTS}

The authors acknowledge the collaboration of ESCOFET S.A. in the performance of the experimental program. The first author also acknowledges the Spanish Ministry of Education, Culture and Sport for providing support through the grant FPU.

\section{REFERENCES}

[1] Giaccio, G., Tobes, J. M., \& Zerbino, R. (2008). "Use of small beams to obtain design parameters of fibre reinforced concrete." Cement and Concrete Composites, 30(4), 297-306.

[2] Awinda, K., Chen, J., \& Barnett, S. J. (2016). "Investigating geometrical size effect on the flexural strength of the ultra high performance fibre reinforced concrete using the cohesive crack model." Constr. Build. Mater., 105, 123-131.

[3] Mahmud, G. H., Yang, Z., \& Hassan, A. M. T. (2013). "Experimental and numerical studies of size effects of Ultra High Performance Steel Fibre Reinforced Concrete (UHPFRC) beams." Construction and Building Materials, 48, 1027-1034.

[4] Karihaloo, B. L., Murthy, a. R., \& Iyer, N. R. (2013). "Determination of sizeindependent specific fracture energy of concrete mixes by the tri-linear model." Cement and Concrete Research, 49, 82-88.

[5] International Federation for Structural Concrete, fib Model Code for Concrete Structures 2010.

[6] CEN (European Committee for Standardization). (2014). "EN 12390-13:2014. Testing hardened concrete - Part 13: Determination of secant modulus of elasticity in compression." Brussels.

[7] CEN (European Committee for Standardization). (2009). "EN 12390-3. Testing hardened concrete. Part 3: Compressive strength of test specimens." Brussels.

[8] CEN (European Committee for Standardization). (2007). "EN 14651:2007. Test method for metallic fibre concrete. Measuring the flexural tensile strength (limit of proportionality (LOP), residual)." Brussels.

[9] Nguyen, D. L., Kim, D. J., Ryu, G. S., \& Koh, K. T. (2013). "Size effect on flexural behavior of ultra-high-performance hybrid fiber-reinforced concrete." Composites: Part B, 45(1), 1104-1116.

[10] Yoo, D. Y., Banthia, N., Kang, S. T., \& Yoon, Y. S. (2016). "Size effect in ultrahigh-performance concrete beams." Eng. Fract. Mech., 157, 86-106.

[11] Dupont, D., \& Vandewalle, L. (2005). "Distribution of steel fibres in rectangular sections." Cement and Concrete Composites, 27(3), 391-398.

[12] Laranjeira, F., Aguado, a., Molins, C., Grünewald, S., Walraven, J., \& Cavalaro, S. (2012). "Framework to predict the orientation of fibers in FRC: A novel philosophy." Cement and Concrete Research, 42(6), 752-768.

[13] De La Fuente, A., Escariz, R. C., De Figueiredo, A. D., Molins, C., \& Aguado, A. (2012). "A new design method for steel fibre reinforced concrete pipes." Construction and Building Materials, 30, 547-555.

[14] Montaignac, R., Massicotte, B., \& Charron, J.P. (2011). "Design of SFRC structural elements: flexural behaviour prediction." Materials and Structures, 45(4), 623-636. 